\title{
Demodex-Associated Bacillus Proteins Induce an Aberrant Wound Healing Response in a Corneal Epithelial Cell Line: Possible Implications for Corneal Ulcer Formation in Ocular Rosacea
}

\author{
Niamb O'Reilly, ${ }^{1}$ Clair Gallagher, ${ }^{2}$ Kishore Reddy Katikireddy, ${ }^{2}$ Martin Clynes, ${ }^{2}$ \\ Finbarr O'Sullivan, ${ }^{2,3}$ and Kevin Kavanagh ${ }^{1,3}$
}

Purpose. The aim of the work presented here was to establish the response of a corneal epithelial cell line (hTCEpi) to protein extracted from a bacterium (Bacillus oleronius) previously isolated from a Demodex mite from a rosacea patient.

Methods. The response of the corneal epithelial cell line to Bacillus proteins was measured in terms of alterations in cell migration and invasiveness. Changes in the expression of metalloproteinase genes and proteins were also assessed.

REsults. The results indicated increased cell migration (14.5fold, $P=0.001$ ) as measured using 8 - $\mu \mathrm{m}$ PET inserts (BD Falcon) in a transwell assay and invasiveness (1.7-fold, $P=$ 0.003 ) as measured using $8-\mu \mathrm{m}$ Matrigel (BD Biocoat) invasion inserts in a 24-well plate assay format, following exposure to the Bacillus proteins. Cells exposed to the Bacillus protein showed a dose-dependent increase in expression of genes coding for matrix metalloprotease (MMP)-3 (61-fold) and MPP-9 (301-fold). This dose-dependent increase in gene expression was also reflected in elevated levels of MMP-9 protein (1.34fold, $P=0.033$ ) and increased matrix metalloprotease activity (1.96-fold, $P=0.043$ ) being present in the culture supernatant. Cells also displayed reduced levels of $\beta$-integrin (1.25-fold, $P=$ 0.01 ), indicative of increased motility and elevated levels of vinculin (2.7-fold, $P=0.0009)$, suggesting altered motility.

Conclusions. The results indicate that exposure of corneal epithelial cells to Bacillus proteins results in an aberrant wound healing response as visualized using a scratch wound assay. These results suggest a possible link between the high density of Demodex mites on the eyelashes of ocular rosacea patients and the development of corneal ulcers. (Invest Opbthalmol Vis Sci. 2012;53:3250-3259) DOI:10.1167/ iovs.11-9295

From the ${ }^{1}$ Department of Biology, NUI Maynooth, Co. Kildare, Ireland; and the ${ }^{2}$ National Institute for Cellular Biotechnology, DCU, Glasnevin, Dublin 9, Ireland.

${ }^{3}$ These authors contributed equally to the work presented here and should therefore be regarded as equivalent authors.

Supported by the Translational Research Hub (TRH) Lead Fund Programme and NUI Maynoonth through a postgraduate scholarship (NO'R).

Submitted for publication December 12, 2011; revised March 2, 2012; accepted April 5, 2012.

Disclosure: N. O'Reilly, None; C. Gallagher, None; K.R. Katikireddy, None; M. Clynes, None; F. O'Sullivan, None; K. Kavanagh, None

Corresponding author: Kevin Kavanagh, Medical Mycology Unit, Department of Biology, NUI Maynooth, Co. Kildare, Ireland; Phone: +353-1-7083859; Fax: +353-1- 7083845; kevin.kavanagh@nuim.ie.
R osacea is a chronic inflammatory dermatological condition 1 that affects the skin of the face and the eyes. ${ }^{1}$ A number of forms of rosacea are recognized, including papulopustular, erythematotelangiectatic, ocular, and phymatous. ${ }^{1,2}$ Ocular rosacea affects the eyes and the eyelids, causing symptoms such as blepharitis and keratitis; and up to half of those diagnosed with facial rosacea also manifest ocular symptoms. ${ }^{3,4}$ Corneal (sterile) ulcers are associated with severe cases of ocular rosacea and can lead to deterioration of vision and potentially blindness in affected eyes. ${ }^{5}$

While the classification and grading of rosacea is wellestablished, ${ }^{6}$ there is no agreement of the etiological agent(s) responsible for this condition nor its pathogenesis. ${ }^{7}$ Factors such as alteration in the innate immune response, vascular changes in the skin, and the presence of a reactive oxygen species within the skin have been suggested to play a role in the induction and persistence of the condition. ${ }^{2,7}$ Patients affected with rosacea display a higher density of facial mites, Demodex folliculorum, than unaffected controls, ${ }^{8-11}$ although the significance of this observation has never been explained. A bacterium (Bacillus oleronius) isolated from a Demodex folliculorum mite from a patient with papulopustular rosacea produced proteins that induced an inflammatory immune response in $72 \%$ of rosacea patients but only $29 \%$ of controls ( $P$ $=0.01) .^{12}$ The bacterium was previously isolated from the digestive tract of a termite where it may facilitate digestion. ${ }^{13} \mathrm{~A}$ strong correlation has been established between ocular Demodex inflammation and serum reactivity to these bacterial proteins in patients with ocular rosacea. ${ }^{14}$ In addition, eye lid margin inflammation $(P=0.040)$ and facial rosacea $(P=0.009)$ were found to correlate with reactivity to these proteins. ${ }^{14}$ These two studies ${ }^{12,14}$ suggest a possible role for bacterial proteins in the etiology of rosacea; and the objective of the work presented here was to examine how these proteins might produce some of the pathologies associated with ocular rosacea, especially alterations to the corneal surface.

Corneal epithelial cells represent an excellent model for studying the interaction of pathogens with the corneal surface. ${ }^{15,16}$ Hozono et al. ${ }^{15}$ investigated the response of corneal epithelial cells to flagellin isolated from pathogenic and nonpathogenic bacteria. Human corneal epithelial cells expressed higher levels of toll-like receptor (TLR)- 5 mRNA and protein in response to flagellin isolated from ocular pathogens (e.g., Pseudomonas aeruginosa) compared with nonpathogenic bacteria (e.g., Bacillus subtilis). Proinflammatory cytokines IL-6 and IL-8 were also induced at higher levels in response to pathogenic flagellin. Maltseva et al. ${ }^{16}$ characterized the response of human corneal epithelial cells, exposed to contact lenses, to $P$. aeruginosa supernatant proteins. Corneal epithelial cells normally increased expres-

Investigative Ophthalmology \& Visual Science, May 2012, Vol. 53, No. 6 Copyright 2012 The Association for Research in Vision and Ophthalmology, Inc. 
sion of the antimicrobial peptide human $\beta$-defensin (hBD)-2 in response to $P$. aeruginosa; however, in cells that were previously exposed to contact lenses in vitro, this upregulation was blocked.

The human telomerase immortalized corneal epithelial cell line (hTCEpi) was generated by infecting primary cultures of human corneal epithelial cells with a retroviral vector encoding telomerase reverse transcriptase (hTERT). The purpose of this cell line was to provide a model for the study of molecular mechanisms involved in human corneal cell differentiation. ${ }^{17}$ The cell line was recently used to investigate the role of plasma membrane calcium-ATPase expression in a wound healing model. ${ }^{18}$

Ocular symptoms are present in up to $50 \%$ of rosacea patients ${ }^{4}$; therefore, this study employed a corneal epithelial cell line to examine the potential cellular changes that could contribute to the symptoms of ocular rosacea. Given the fact that rosacea patients in two earlier studies $^{12,14}$ showed reactivity to proteins produced by B. oleronius, the hope was to establish how these antigens interact with corneal epithelial cells as this might give an insight into how these antigens disrupt the cornea in vivo and contribute to the formation of corneal ulcers.

\section{Materials and Methods}

\section{Preparation of Bacterial Antigens}

Protein was isolated from B. oleronius as described previously. ${ }^{12,14}$ The protein was resuspended in PBS at a concentration of $200 \mu \mathrm{g} / \mathrm{mL}$ and subjected to anion exchange separation via a preparative liquid chromatography system, FPLC (fast protein liquid chromatography). ${ }^{12}$ Fractions corresponding to the proteins of interest were pooled and precipitated. The protein concentration was determined by Bradford assay and the protein was re-suspended in PBS at a concentration of $200 \mu \mathrm{g} / \mathrm{mL}$. Following separation by SDS-PAGE, protein bands (approximately $30-80 \mathrm{kDa}$ ) were visualized by staining with Coomassie blue. These bands were excised, trypsin digested, and subjected to liquid chromatography mass spectrometry analysis. ${ }^{19}$

\section{Human Corneal Epithelial Cells}

hTCEpi cells were maintained in Keratinocyte Growth Medium (KGM)2 supplemented with KGM-2 SingleQuot Kit Supplements \& Growth Factors (Lonza), in a humidified $5 \% \mathrm{CO}_{2}$ incubator at $37^{\circ} \mathrm{C}$, and passaged every 7 to 10 days.

\section{Cell Growth and Motility Assays}

hTCEpi cells were seeded at a density of $4 \times 10^{4}$ cells $/ \mathrm{mL}$ into 24 -well culture dishes and allowed to adhere overnight at $37^{\circ} \mathrm{C}$ and $5 \% \mathrm{CO}_{2}$. The following day, cells were washed and KMG-2 medium was added to the wells. Media with increasing concentrations of the protein preparation $(0.5-6 \mu \mathrm{g} / \mathrm{mL})$ were added to relevant wells and incubated for 5 days at $37^{\circ} \mathrm{C}$ in a humidified $5 \% \mathrm{CO}_{2}$ incubator. Growth medium was refreshed every 2 days. The assay was evaluated at day 5 by staining with $0.05 \%$ (w/v) crystal violet (Sigma-Aldrich, Steinheim, Germany) and eluting with $33 \%$ (w/v) glacial acetic acid. The absorbance was read on a spectrophotometer at $570 \mathrm{~nm}$.

In order to evaluate cell migration, hTCEpi cells were exposed to purified protein preparation $(2$ or $6 \mu \mathrm{g} / \mathrm{mL}$ ). Cells were trypsinized and re-suspended at a concentration of $4 \times 10^{4} / \mathrm{mL}$ in the relevant medium. Treated media $(500 \mu \mathrm{L})$ were applied to a 24 -well plate and an $8-\mu \mathrm{m}$ pore size insert (BD Falcon) was added to the wells before the cells $(500 \mu \mathrm{L})$ were placed inside the insert. Cells were incubated for 24 hours in a humidified $5 \% \mathrm{CO}_{2}$ incubator at $37^{\circ} \mathrm{C}$. The under surface was gently rinsed with PBS and stained with $0.25 \%(\mathrm{w} / \mathrm{v})$ crystal violet (Sigma-Aldrich) for 10 minutes, rinsed again with sterile water, and allowed to dry. The inserts were viewed under the microscope and the number of cells/field in five random fields were counted at $\times 200$ magnification. To perform the invasion assays, hTCEpi cells $\left(4 \times 10^{4}\right)$ were treated as described in the migration assay, but were placed in an $8.0-\mu \mathrm{m}$ pore size pre-Matrigel coated invasion chamber insert (BD BioCoat; R\&D Systems, Abingdon, UK). The same staining and counting protocol was followed as for the migration assay.

\section{Scratch Wound Assay}

To test the effect of bacterial protein on wound healing, hTCEpi cells $\left(6 \times 10^{4} / \mathrm{mL}\right)$ were cultured in 6-well plates and supplemented with KGM-2 until a confluent layer was achieved. A scratch wound was made across the cell layer using a $200-\mu \mathrm{m}$ pipette tip. The plate was washed with PBS to remove cell debris and then incubated in the presence of the purified bacterial protein preparation $(2,4$, or $6 \mu \mathrm{g} /$ $\mathrm{mL}$ ). Cells exposed to normal medium were used as controls. The effect on cell mobility was visualized over 72 hours.

\section{Isolation of Protein from Corneal Epithelial Cells}

hTCEpi cells $\left(6 \times 10^{4} / \mathrm{mL}\right)$ were seeded in 6-well culture dishes and exposed to protein preparation $(2$ or $6 \mu \mathrm{g} / \mathrm{mL}$ ) for 5 days. Lysis buffer consisting of $0.25 \mathrm{M}$ Tris $\mathrm{HCl}(\mathrm{pH} \mathrm{7.2)}$ ) and 2.5\% SDS was heated to $95^{\circ} \mathrm{C}$ and added in a volume dependent on the consistency of the lysate $(500 \mu \mathrm{L})$. Protein concentrations were determined using the Bio-Rad protein assay, according to manufacturer's instructions (Bio-Rad). The protein was mixed with Lamelli sample buffer (Bio-Rad) and frozen at $-20^{\circ} \mathrm{C}$ until required.

\section{Electrophoresis and Western Blotting}

Protein $(20 \mu \mathrm{g})$ was resolved by application to a $10 \%$ SDS-PAGE under reducing conditions. Separated proteins were transferred to nitrocellulose membrane (Amersham), using a semidry blotter (Bio-Rad) in Towbin transfer buffer ( $25 \mathrm{mM}$ Tris, $192 \mathrm{mM}$ Glycine, $20 \%$ methanol in $\mathrm{dH}_{2} \mathrm{O}, \mathrm{pH}$ 8.3).

Membranes were blocked using 1\% dried milk powder (Marvel) in tris buffered saline (TBS) (25 mM Tris-HCl, pH 7.4, $150 \mathrm{mM} \mathrm{NaCl}, 2.7$ $\mathrm{mM} \mathrm{KCl}$ ) with $0.1 \%$ tween (Sigma) for 1 hour at room temperature. Primary antibodies were diluted as follows: anti-GAPDH (raised in mouse [Sigma Aldrich]) 1:2000; anti- $\beta$ 1-Integrin (raised in mouse [Chemi-Con, Billerica, MA]) 1:1000; anti-vinculin (raised in rabbit [Cruz Biotechnology, Santa Cruz, CA]) 1:500; MMP-9 (raised in goat, R\&D Systems) 1:1000; and incubated at $4^{\circ} \mathrm{C}$ overnight.

The relevant horseradish peroxidase-linked secondary antibody (HRP-linked rabbit antisera at a dilution of 1/1000, or HRP-linked mouse antisera at a dilution of 1/2000) was applied and incubated at room temperature for 2 hours. Enhanced chemiluminescence (PerkinElmer, Bridgeville, PA) was used to develop reactive protein bands and immuno-bands were quantified by densitometry using Image-J software.

\section{MMP-9 Zymography}

Cell culture media were collected and concentrated $3 \times$ using a spin column with a 3000 molecular weight cut off. Samples were mixed with Tris-Glycine SDS sample buffer $(\times 2)$. Novex zymogram gels (Invitrogen) were prepared and run according to manufacturer's instructions. Gels were incubated overnight at $37^{\circ} \mathrm{C}$ in developing buffer and stained the following day with Colloidal blue staining.

\section{RNA Extraction and Gene Expression Analysis}

hTCEpi cells $\left(6 \times 10^{4} /\right.$ well $)$ were seeded in 6 -well culture dishes and exposed to the bacterial protein preparation $(0,2,4$, or $6 \mu \mathrm{g} / \mathrm{mL}$ in 2 $\mathrm{mL}$ total volume) for 5 days, with feeding/ treatment on alternate days. 
Cells were washed twice in PBS and harvested by incubating cells with $0.25 \%$ trypsin $/ 0.022 \%$ EDTA solution at $37^{\circ} \mathrm{C}$ for 2 minutes, followed by scraping, centrifugation, and removal of supernatant.

Tri-reagent (1 mL) (Sigma-Aldrich) was added to the pellet and RNA extracted according to manufacturer's instructions. RNA was quantified using a spectrophotometer (NanoDrop 1000 Spectrophotometer; NanoDrop Technologies, Wilmington, DE) and concentrations normalized prior to cDNA synthesis. cDNA was synthesized using a highcapacity RNA to CDNA kit (Applied Biosystems, Carlsbad, CA) and amplification of MMP-3 and MMP-9 targets performed using TaqMan Gene Expression Assays Hs00968308_m1 and Hs00957555_m1, ABI 7500 Fast Real-time PCR system (Applied Biosystems), and the fast PCR amplification protocol (initial denaturation $95^{\circ} \mathrm{C}$ per 20 seconds; 40 cycles of denaturation $95^{\circ} \mathrm{C}$ per 3 seconds; annealing-extension $60^{\circ} \mathrm{C}$ per 30 seconds). Biological and technical replicates were analyzed for all samples and no-reverse transcriptase-controls run in parallel to confirm that DNA contamination had not occurred.

Resultant cycle threshold $(\mathrm{Ct})$ values were normalized against human GAPDH endogenous control expression (Hs99999905_m1) and changes in expression calculated using the $\mathrm{RQ}=2^{-\Delta \Delta \mathrm{Ct}}$ equation.

\section{Statistics}

For reverse transcriptase PCR expression analysis, Pearson's correlation was used to determine the relationship between treatment and target expression using delta $\mathrm{Ct}$. As delta $\mathrm{Ct}$ values relate to cycle number (whereby increases in $\mathrm{Ct}$ equate to lower expression), correlation values were multiplied by -1 to allow the direction of the correlation to be easily interpreted. All experiments were performed on three independent occasions. The results presented are given as the mean \pm SE. Student's $t$-tests were performed using GraphPad Prism software and samples with a $P$ value $\leq 0.05$ were deemed significant.

\section{Results}

\section{Bacterial Proteins Identified by LC/MS}

A number of proteins were present in the purified fraction and these were excised from 1-D SDS-PAGE gels, trypsin digested, and identified by LC/MS The results indicated that the preparation contained a number of proteins capable of provoking a strong immune response including peptidoglycan synthesis protein, flagellin, KatE1, superoxide dismutase, alkyl hydroperoxide reductase and elongation factor $\mathrm{G}^{20}$

\section{Effect of Bacillus Protein on the Growth of hTCEpi Cells}

In order to assess the effect of the Bacillus proteins on the growth of corneal epithelial cells, hTCEpi cells were grown to confluency, trypsinized, and seeded in 24-well plates as described. Following incubation at $37^{\circ} \mathrm{C}$ for 24 hours, cells were exposed to different concentrations of Bacillus protein $(0.5 \mu \mathrm{g}-6 \mu \mathrm{g} / \mathrm{mL})$ and incubated at $37^{\circ} \mathrm{C}$ for 5 days. The results (Fig. 1) indicate that the Bacillus proteins dose dependently inhibited cell growth. At a protein concentration of $2 \mu \mathrm{g} / \mathrm{mL}$, cell growth was inhibited by $26 \%(P=0.018)$ and at $6 \mu \mathrm{g} / \mathrm{mL}$, cell growth was inhibited by $75 \%(P=0.0003)$. This growth inhibition appears to be antigen specific and not due to increasing concentration of protein in the media, as demonstrated by the addition of $6 \mu \mathrm{g} / \mathrm{mL}$ BSA (Fig. 1).

\section{Effect of Bacillus Protein on Cell Mobility and Wound Healing Response}

Exposing the hTCEpi cell line to increasing concentrations of Bacillus protein resulted in an increase in cell mobility.
Exposure of cells to an antigen concentration of $2 \mu \mathrm{g} / \mathrm{mL}$ produced a 3.6 -fold increase in mobility $(P=0.001)$ and exposure of cells to $6 \mu \mathrm{g} / \mathrm{mL}$ of the antigens produced a 15 -fold increase in mobility $(P=0.0001)$, compared with the control (Fig. 2) indicating a dose-dependent response.

In order to examine how increased cell mobility might affect the wound response of corneal epithelium, wound assays were performed as described. The results (Fig. 3) indicate that after 72 hours, the site of the wound in the control was still visible. The control wound showed signs of closing with the cells migrating inwards as a continuous cell sheet. In contrast, those cells that had been exposed to Bacillus protein concentrations of 2 or $6 \mu \mathrm{g} / \mathrm{mL}$ showed cells migrating either as single cells or as groups of cells. The closure of the wounds exposed to Bacillus protein was due mainly to these migratory cells rather than migration of the edge of the epithelial cell sheet. These results suggest that exposure to the Bacillus proteins induces increased cell mobility which, at the monolayer level, is visible as disruption of the layer integrity.

\section{The Effect of Bacillus Proteins on Invasion and MMP-9 Production in Corneal Epithelial Cells}

To investigate if the alterations in cell mobility following exposure to Bacillus protein was also accompanied by changes in cell invasiveness, invasion assays were performed as described using $8.0-\mu \mathrm{m}$ pore size inserts. Results of these assays (Fig. 4) revealed an increase in hTCEpi cell invasiveness of 1.7 -fold $(P=0.003)$ in response to exposure to $2 \mu \mathrm{g} /$ $\mathrm{mL}$ of the Bacillus protein and by 1.8 -fold $(P=0.01)$ in response to $6 \mu \mathrm{g} / \mathrm{mL}$ of the Bacillus protein, compared with control cells.

MMPs are a family of enzymes involved in the degradation of extracellular matrix components such as collagens, fibronectin, and laminin that are involved in normal processes such as angiogenesis and wound healing. ${ }^{21}$ Over-expression of these enzymes has been implicated in the pathogenesis of rosace ${ }^{7}$ and there is evidence that the production of MMPs is increased by a number of factors, including exposure to UV radiation, the presence of reactive oxygen species, and inflammation. ${ }^{22-24}$ Increased expression of MMP-2 and -9 has been demonstrated in diseases of the ocular surface including ocular rosacea, where tear fluid showed elevated levels of MMP-9. ${ }^{25}$ Expression analysis of cells exposed to Bacillus protein showed a positive correlation between treatment and target expression with dose-dependent increases in expression indicated for both MMP-3 ( $\mathrm{r}=0.8888, P=$ $1.106 \mathrm{e}-4)$ and MMP-9 $(\mathrm{r}=0.8988, P=7.006 \mathrm{e}-5)$. MMP-3 has been shown to activate MMP-9 in vivo; and increases in expression for both targets were significant, with maximal fold changes of $61(P=0.005049388)$ and $301 \quad(P=$ 0.004345987 ) observed respectively for MMP-3 and MMP-9 at the maximal treatment concentration of $6 \mu \mathrm{g} / \mathrm{mL}$ (Figs. 5 and 6).

Western blot analysis of MMP-9 in the culture supernatant of cells exposed to Bacillus protein also demonstrated an increase in MMP-9 expression (1.34-fold, $P=0.033$ ) when exposed to $2 \mu \mathrm{g} / \mathrm{mL}$ of Bacillus protein (Fig. 7). Gelatin zymograms were performed to investigate whether the increase in MMP-9 protein expression in the culture supernatant of cells exposed to Bacillus protein was accompanied by an increase in its activity. Cells exposed to $4 \mu \mathrm{g} / \mathrm{mL}$ of the purified bacterial protein preparation showed an increase in MMP-9 or gelatinase activity of 1.96 -fold $(P=0.043)$ when compared with untreated control cells (Fig. 8). 


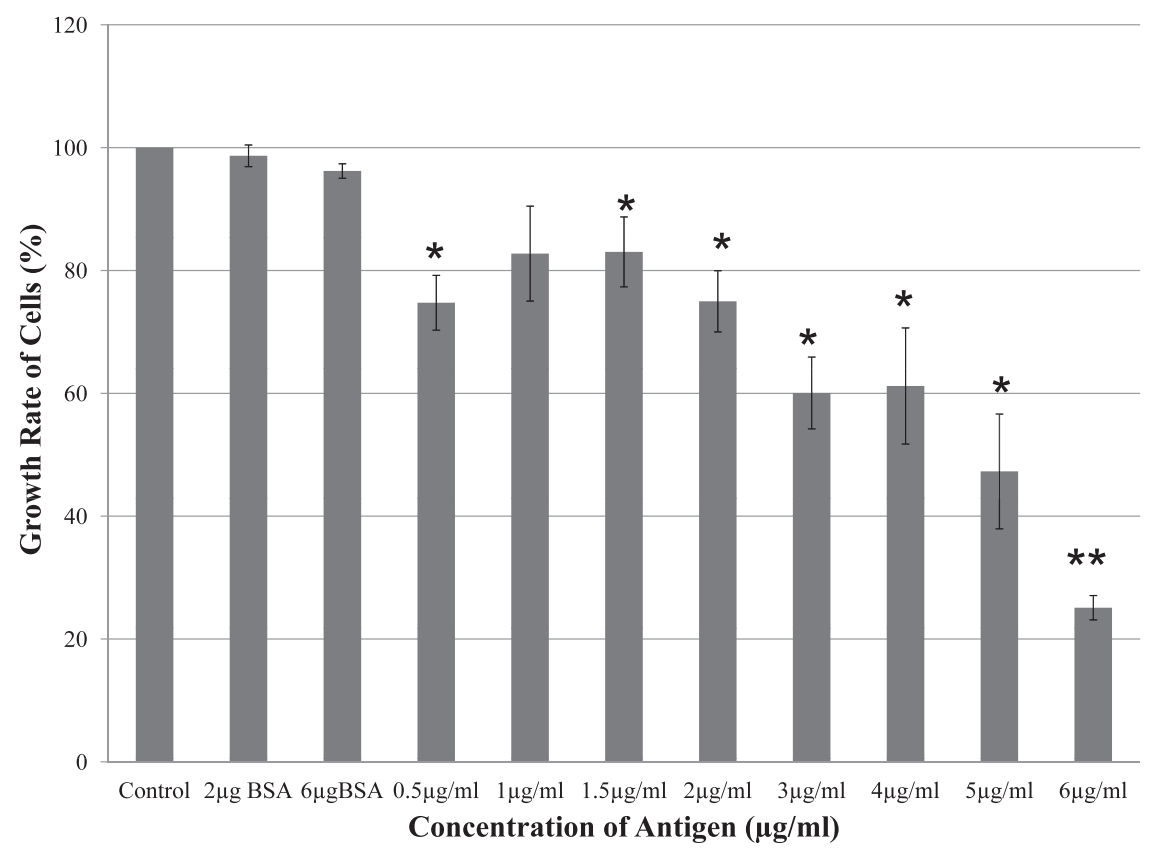

FIGURE 1. The effect of Bacillus oleronius proteins on hTCEpi cell growth after 5 days. Following 5 days of exposure to the bacterial protein ( $2 \mu \mathrm{g} / \mathrm{mL}$ ), hTCEpi cell growth was inhibited by $26 \%(P=0.018)$ and by $75 \%(P=0.0003)$ following exposure to $6 \mu \mathrm{g} / \mathrm{mL}$. The results presented here are a combination of three replicates with statistical significance calculated by comparing treatments to control. ${ }^{*} P<0.05$, ${ }^{* *} P<0.01$.

\section{Assessment of the Effect of Bacillus Protein on $\beta 1$ - Integrin and Vinculin Expression}

Since increased migration was induced by exposure of cells to Bacillus proteins, it was decided to investigate the expression of proteins involved in cell movement and interaction. $\beta 1$ integrin is involved in cell binding to extracellular matrix components such as fibronectin, laminin, and collagens, and is involved in cellular mobility, adhesion, and signaling. ${ }^{25,26}$ The expression of this protein decreased 1.25 -fold $(P=0.01)$ in

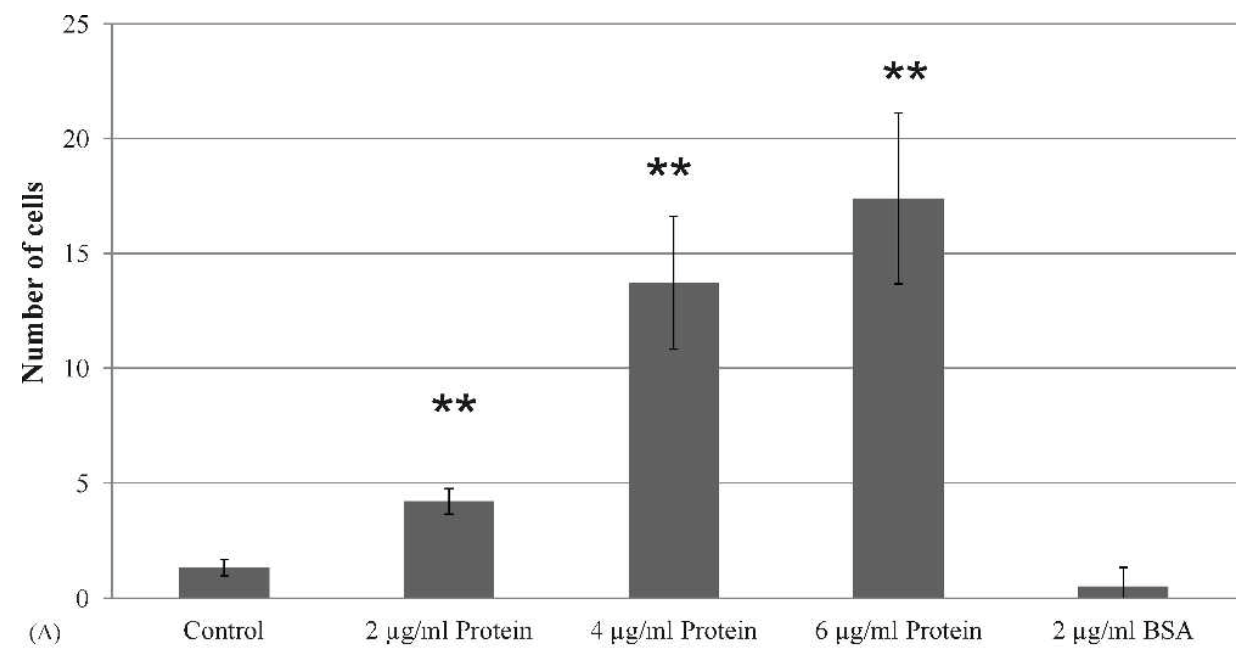

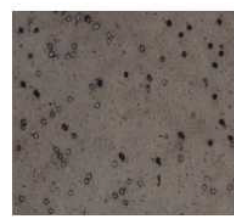

(B)

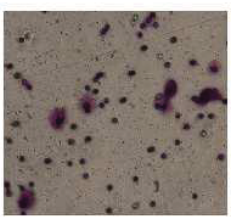

$2 \mu \mathrm{g} / \mathrm{ml}$

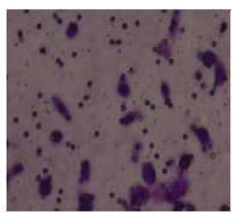

$4 \mu \mathrm{g} / \mathrm{ml}$

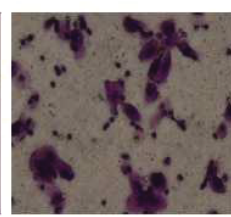

$6 \mu \mathrm{g} / \mathrm{ml}$

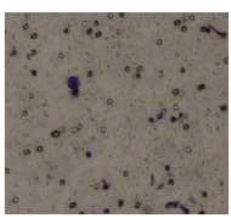

$2 \mu \mathrm{g} / \mathrm{ml}$ BSA

FIGURE 2. (A) Effect of $B$. oleronius protein on the migration of hTCEpi cells. Migration increased 3.6 -fold $(P=0.001)$ in response to $2 \mu \mathrm{g} / \mathrm{mL}$ of the protein and by 14.5 -fold in response to $6 \mu \mathrm{g} / \mathrm{mL}(P=0.0001)$ when compared with control cells. (B) Images of increased migration of hTCEpi cells. Images were taken with an Olympus microscope at $\times 20$ magnification and are representative of three repeats of the assay. 
Control
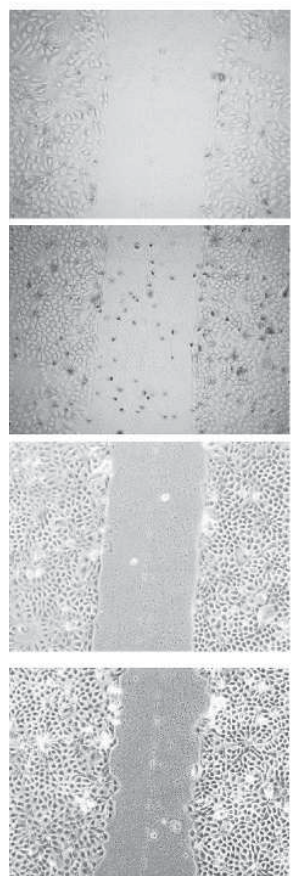

$2 \mu \mathrm{g} / \mathrm{ml}$ Protein
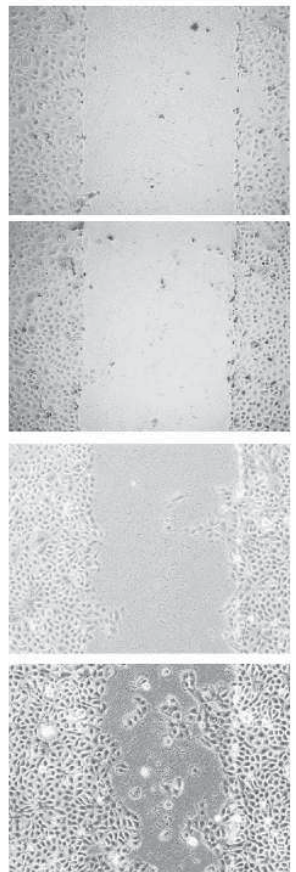

$6 \mu \mathrm{g} / \mathrm{ml}$ Protein

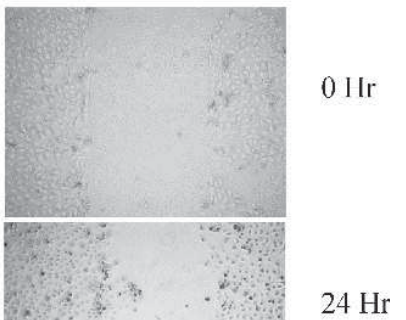

$24 \mathrm{Hr}$

$48 \mathrm{Hr}$

$72 \mathrm{Hr}$

FIgURE 3. Wound healing in hTCEpi cells treated with purified $B$. oleronius protein. Images were taken with a Leica camera at $\times 20$ magnification and are representative of three repeats of this assay. Migration of cells at the leading edge of the wound was increased in cells treated with the antigen compared with control cells.

hTCEpi cells exposed to $4 \mu \mathrm{g} / \mathrm{mL}$ of the bacterial protein (Fig. 9). Decreased expression of this protein can facilitate migration of cells since the cells become less adherent to the extracellular matrix. ${ }^{28,29}$

Vinculin is a membrane cytoskeletal protein involved in linkage of integrins to the actin filaments of the cytoskeleton and is involved in anchoring F-actin to the membrane. ${ }^{27,30}$ The expression of vinculin was quantified by Western blotting (Fig. 10). The expression of vinculin increased 2.05 -fold $(P=$ $0.0026)$ and 2.7 -fold $(P=0.0009)$ in cells in response to exposure to $4 \mu \mathrm{g} / \mathrm{mL}$ and $6 \mu \mathrm{g} / \mathrm{mL}$ of the purified protein preparation, respectively.

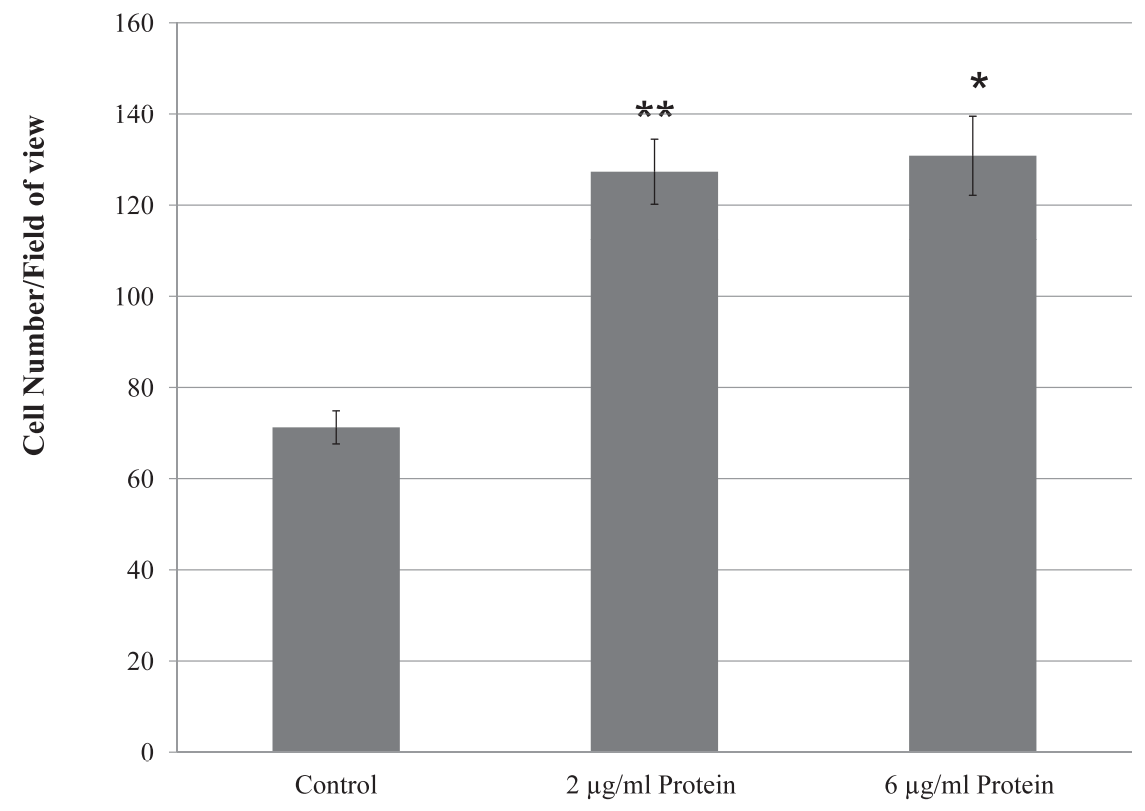

FIgURE 4. The effect of $B$. oleronius proteins on the invasion of hTCEpi cells through a Matrigel membrane. These data are representative of two replicates of the assay where * denotes $P<0.05$ while ${ }^{* *}$ is $P<0.01$. hTCEpi cell invasion increased 1.7 -fold $(P=0.003)$ in response to $2 \mu \mathrm{g} / \mathrm{mL}$ of the protein. Membranes were viewed at $\times 40$ magnification and $\times 3$ fields of view were counted per treatment for each replicate in the assay. 


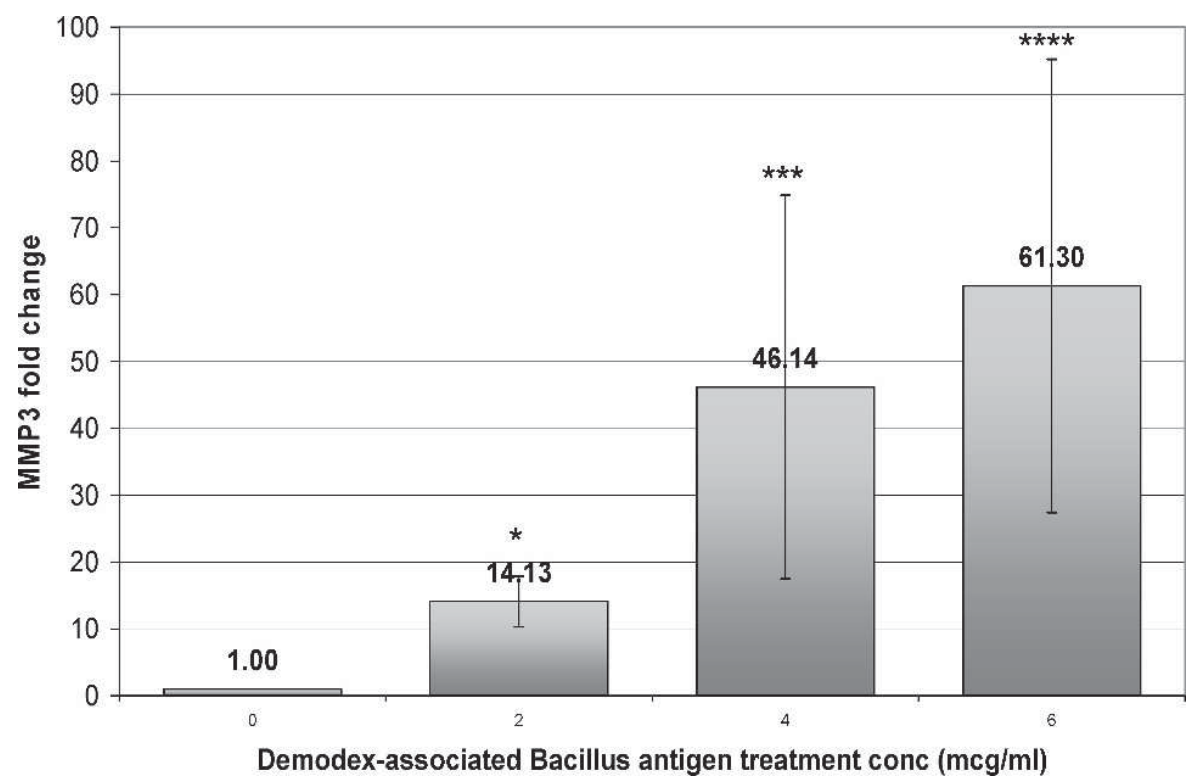

FIGURE 5. The effect of B. oleronius proteins on the expression of MMP-3 in hTCEpi cells measured by rt-PCR. The effect of Demodex-associated B. oleronius protein on MMP3 expression in hTCEPi cells was investigated using reverse transcriptase PCR (mean fold change \pm SE). Treatment with $B$. oleronius protein induced MMP-3 up-regulation in a dose-reflective manner $(\mathrm{r}=0.8888, P=1.106 \mathrm{e}-4)$; with a 14-, 46-, and 61-fold increase in expression observed upon treatment with 2,4 , and $6 \mu \mathrm{g} / \mathrm{mL}$ of purified protein respectively. The results are presented as a fold change in expression compared with the no-treatment control, where a significant increase of $P<0.05$ is denoted by $*$; $<<0.001$ by ${ }^{* * *}$; and $P$ $<0.0001$ by ${ }^{* * * * * *}$.

\section{DisCuSSION}

The aim of the work presented here was to characterize the effect of Demodex associated bacterial proteins on a corneal epithelial cell line (hTCEpi), as this might give an insight into the interactions of such proteins with the corneal surface in vivo and demonstrate how these might contribute to some of the pathologies associated with ocular rosacea. It has been suggested previously that dysregulation of the innate immune responses may play a significant role in the induction and persistence of rosacea ${ }^{1,7,12,14,31}$; and it was postulated that the presence of Demodex-associated bacterial proteins on the

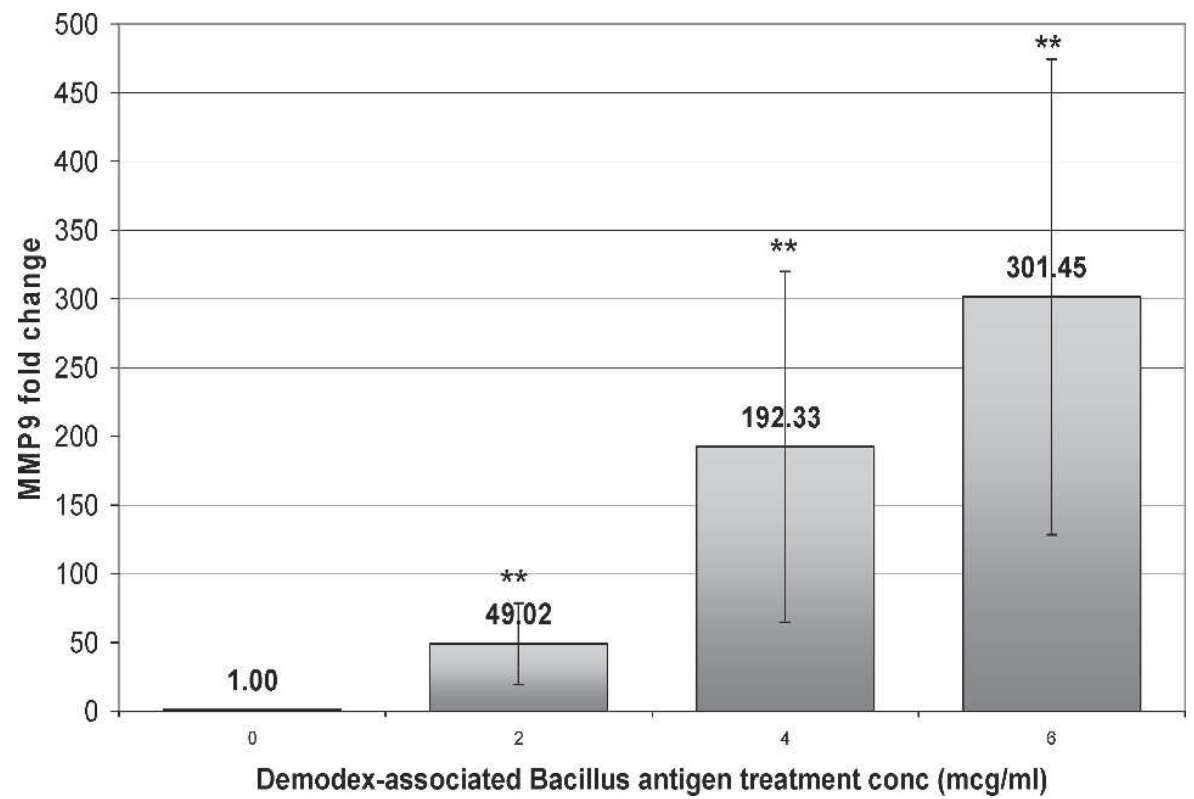

Figure 6. The effect of B. oleronius proteins on the expression of MMP-9 in hTCEpi cells measured by rt-PCR. The effect of Demodex-associated B. oleronius protein treatment on MMP-9 expression in hTCEPi corneal epithelial cells was investigated using reverse transcriptase PCR (mean fold change $\pm \mathrm{SE}$ ). Treatment with B. oleronius proteins induced MMP-9 up-regulation in a dose-reflective manner $(\mathrm{r}=0.8988, P=7.006 \mathrm{e}-5)$; with a 49-, 192-, and 301-fold increases in expression observed upon treatment with 2,4 , and $6 \mu \mathrm{g} / \mathrm{mL}$ of purified protein, respectively. The results are presented as a fold change in expression compared with the no-treatment control, where a significant increase of $P<0.01$ is denoted by **. 


\section{Control $\quad 2 \mu \mathrm{g} / \mathrm{ml} \quad 4 \mu \mathrm{g} / \mathrm{ml} \quad 4 \mu \mathrm{g} / \mathrm{ml} \mathrm{BSA}$}

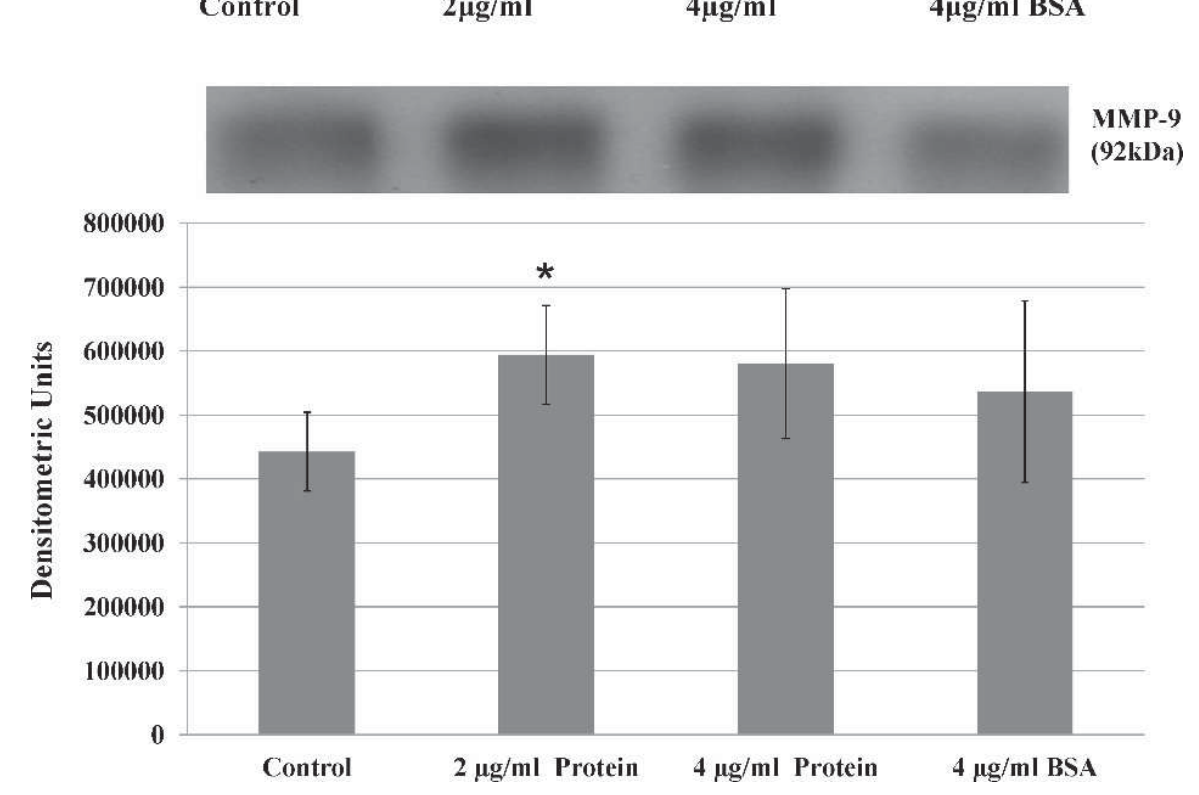

FIGURE 7. The effect of B. oleronius proteins on the expression of MMP-9 in hTCEpi cells measured by Western blotting. Graph represents densitometric analysis of the blots with significant differences denoted by * were $P<0.05$. MMP-9 protein expression was significantly increased by 1.34-fold $(P=0.033)$ in corneal cells exposed to $2 \mu \mathrm{g} / \mathrm{mL}$ of B. oleronius proteins.

corneal surface might induce an aberrant wound healing response that could lead to tissue degradation.

In cases of ocular rosacea, sterile ulcers can form when corneal epithelial surface integrity is challenged and limbal stem cells cannot replenish the corneal surface. ${ }^{32}$ This can occur in cases of chronic inflammation such as that observed in rosacea. ${ }^{5}$ As a result, conjunctival epithelial cells begin to migrate past the limbal region to the corneal surface. Conjunctival cells produce blood vessels that can cause visual impairment due to the loss of clarity of the corneal surface.
Phlyctenule lesions develop and corneal thinning and ulceration can occur in severe cases of rosacea. ${ }^{4}$

Demodex mites reside in the pilosebaceous units of the skin and on eyelashes. 5,9,33 Elevated densities of Demodex mites are a feature of papulopustular ${ }^{8,9}$ and ocular ${ }^{14,33}$ rosacea, but their role in the disease is unexplained. Upon death, the mites may cause local inflammation by release of bacterial endosymbionts and related antigens into the surrounding tissue; and these antigens may be present in the tears and on the corneal surface. The increased reactivity of rosacea patient sera to Bacillus

\section{Control $\quad 2 \mu \mathrm{g} / \mathrm{ml} \quad 4 \mu \mathrm{g} / \mathrm{ml} \quad 4 \mu \mathrm{g} / \mathrm{ml}$ BSA}
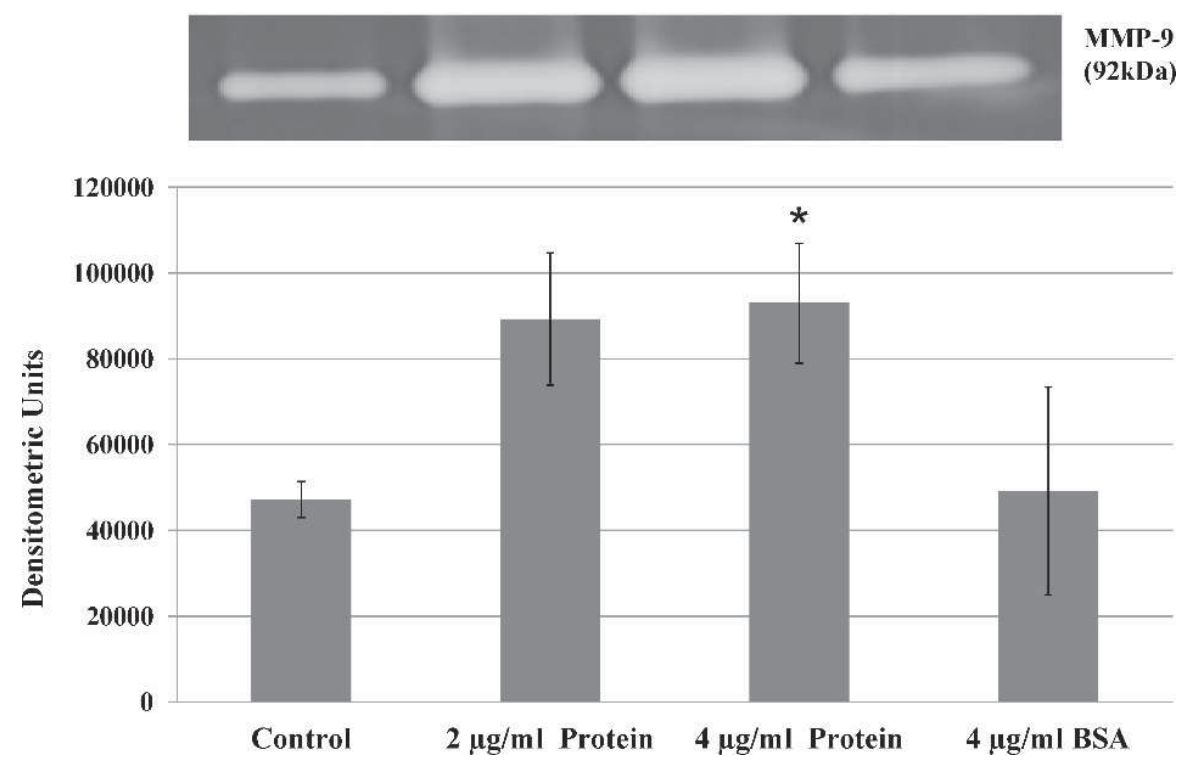

FIGURE 8. The effect of B. oleronius proteins on the activity of MMP-9 in hTCEpi cells measured by Zymography. Graph represents densitometric analysis of the zymograms with significant differences denoted by * where $P<0.05$. MMP-9 protein activity was significantly increased by 1.96 -fold $(P=0.043)$ in corneal cells exposed to $2 \mu \mathrm{g} / \mathrm{mL}$ of $B$. oleronius proteins. 

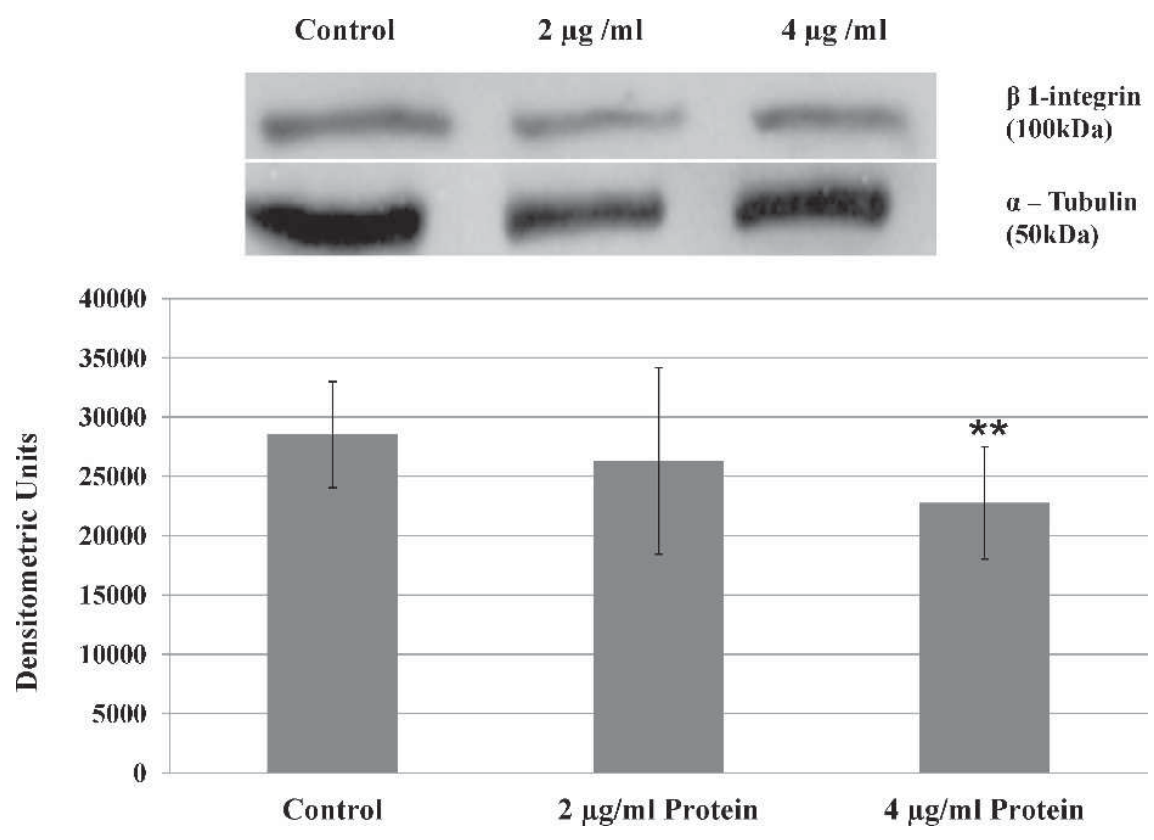

FIGURE 9. The effect of B. oleronius proteins on the expression of $\beta-1$ integrin by hTCEpi cells measured by Western blotting. Densitometric analysis revealed a fold change in expression of $\beta 1$-integrin of $1.25(P=0.01)$ following exposure to $4 \mu \mathrm{g} / \mathrm{mL}$ of the bacterial proteins. $P \leq 0.01$ is denoted by ${ }^{*}$.

proteins was previously demonstrated, thus indicating a possible role for this bacterium in the induction of the condition. ${ }^{12,14}$ Exposure of hTCEpi cells to Bacillus proteins resulted in reduced growth (Fig. 1); however, there was an increase in the mobility of the cells (Figs. 2,3) and this was reflected in an increase in vinculin protein expression (Fig. 10). In organ culture systems, vinculin has been shown to increase in expression in rat corneal epithelial wound healing. ${ }^{30}$
The exposure of hTCEpi cells to Bacillus proteins resulted in a decrease in the expression of $\beta 1$-integrin (Fig. 9) and a more motile phenotype (Figs. 2, 3). Levels of $\beta 1$-integrins are normally elevated in migrating cells compared with their stationary counterparts. ${ }^{28,34}$ The importance of this elevation in $\beta 1$-integrin-expression in the wound response is seen in knockout animals that show severely impaired wound reepithelialization in their cutaneous tissue. ${ }^{35,36}$
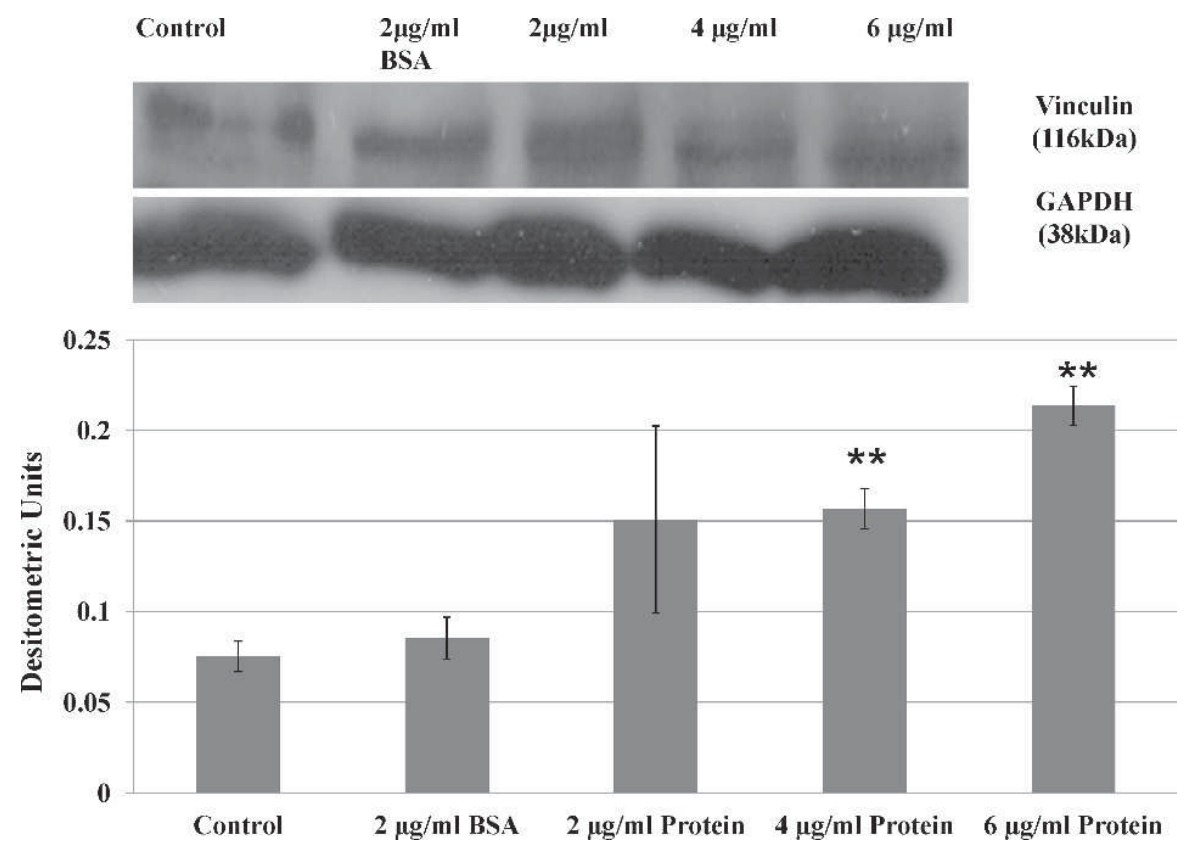

FIGURE 10. The effect of $B$. oleronius proteins on the expression of Vinculin by hTCEpi cells measured by Western blotting. Graph represents densitometric analysis of intensity of vinculin expression with significant differences denoted by $* *$ where $P<0.01$. There was a 2 -fold $(P=0.026)$ increase in expression of vinculin in cells exposed to $4 \mu \mathrm{g} / \mathrm{mL}$ and a 2.7 -fold $(P=0.0009)$ increase in expression following exposure to $6 \mu \mathrm{g} / \mathrm{mL}$ of $B$. oleronius protein. 
Coupled with these changes in mobility and $\beta 1$-integrinexpression, hTCEpi cells exposed to Bacillus proteins demonstrated an increase in invasiveness (Fig. 4). This increase in invasion was reflected in an increase in MMP-9 mRNA expression (Fig. 6); and culture media showed increased MMP9 protein (Fig. 7) and activity (Fig. 8) following exposure to the Bacillus protein preparation. There is evidence that the production of MMPs is upregulated by a number of factors that have been linked to rosacea, ${ }^{26,40}$ including exposure to UV radiation, presence of a reactive oxygen species, and inflammation. ${ }^{22,23,24}$ In particular, increased MMP-9 levels have been observed in patients with ocular rosacea, with $15 \%$ of these patients displaying recurrent corneal erosion. ${ }^{3,37}$ Elevated MMP-9 has been strongly implicated in nonhealing corneal ulcers in humans and therapeutic treatment often includes use of the tetracycline antibiotic. ${ }^{38,39,40}$

Chronic inflammation and loss of corneal epithelium can induce limbal stem cell deficiency and migration of conjunctival epithelial cells to the corneal surface, which leads to neovascularization and contributes to ulceration of the cornea. ${ }^{41}$ It is possible that corneal epithelial cells could be exposed to these antigens in vivo, leading to an accelerated rate of migration and shedding of corneal epithelial cells. The increased expression of vinculin and decreased expression of $\beta 1$-integrin was also recorded in antigen-treated cells, both of which suggest an increased ability of cells to move. Reepithelization involves both the migration and proliferation of cells within the cell sheet. However, these two processes are under different control mechanisms, which at times can be very subtle. For example, an increase in chemokine concentration can induce a switch from a migratory to a proliferating cell type. ${ }^{42}$ Although the migration and proliferation of cells in response to wound healing are separate processes, there is crosstalk between both events. One such crosstalk point occurs between the p38 and ERK1/2 MAPK pathways in corneal wound repair. ERK1/2 has been linked to proliferation; inhibition of this pathway leads to an increase in p38 activation and higher cell migration. ${ }^{43}$ It is not clear from the current data if the Bacillus proteins directly inhibit the proliferative pathway and induce an increase in migratory pathway or if the Bacillus proteins induction of MMP-9 results in disruption of cell adhesion and gap protein complexes, inducing an increase in the migratory cell phenotype. Future studies will investigate if the addition of MMP-9 to the wound can result in increasing the migratory cell phenotype and with what cellular proteins the Bacillus proteins interact.

Elevated Demodex populations are present on the eyelashes of patients with ocular rosacea and a positive correlation between ocular rosacea and serum reactivity to proteins produced by $B$. oleronius, originally isolated from a Demodex mite from a rosacea patient, ${ }^{12}$ has been demonstrated. ${ }^{14}$ Normally the density of Demodex mites is low on eyelashes; but the elevated density of mites, which is characteristic of rosacea, may indicate a greater density of Bacillus and other bacterial antigens being released upon the death of the mite. Study authors postulate that in the case of ocular rosacea, these proteins are shed onto the surface of the cornea where they may induce some of the symptoms of this disease. Understanding the role for bacteria in rosacea will enable the development of more effective and targeted therapies for this condition.

\section{References}

1. Powell FC. Rosacea. N Engl J Med. 2005;352:793-803.

2. Gupta AK, Chaudhry MM. Rosacea and its management: an overview. JEADV. 2005;19:273-285.
3. Jenkins MS, Brown SI, Lempert SL, Weinberg RJ. Ocular rosacea. Am J Ophthalmol. 1979;88:618-622.

4. Oltz M, Check J. Rosacea and its ocular manifestations. Optometry. 2011;82:92-103.

5. Kheirkhah A, Casas V, Li W, Raju VK, Tseng SCG. Corneal manifestations of ocular Demodex infestation. Am J Ophthalmol. 2007;143:743-749.

6. Wilkin J, Dahl M, Detmar M, et al. Standard classification of rosacea: report of the National Rosacea Society Expert Committee on the Classification and Staging of Rosacea. $J$ Am Acad Dermatol. 2002;46:584-587.

7. Yamasaki K, Gallo RL. The molecular pathology of rosacea. $J$ Dermatol Sci. 2009;55:77-81.

8. Bonner E, Eustace P, Powell FC. The Demodex mite population in Rosacea. J Am Acad Dermatol. 1993;28:443-448.

9. Diazperez J. Demodex mites in rosacea. J Am Acad Dermatol. 1994;30:812-813.

10. Erbagci Z, Ozgoztasi O. The significance of Demodex folliculorum density in rosacea. Int J Dermatol. 1998;37: 421-425.

11. Vance J. Demodicidosis-do Demodex mites cause disease? Curr Conc Skin Disorder. 1986;10-18.

12. Lacey N, Delaney S, Kavanagh K, Powell FC. Mite-related bacterial antigens stimulate inflammatory cells in rosacea. Brit J Dermatol. 2007;157:474-481.

13. Kuhnigk T, Borst EM, Breunig A, et al. Bacillus oleronius sp. nov., a member of the hind-gut flora of the termite Reticulitermes santonensis (Feytaud). Can J Microbiol. 1995;41:699-706.

14. Li J, O'Reilly N, Sheha H, et al. Correlation between ocular Demodex infestation and serum immunoreactivity to Bacillus proteins in patients with Facial rosacea. Ophthalmol. 2010; 117:870-877.

15. Hozono Y, Ueta M, Hamuro J, et al. Human corneal epithelial cells respond to ocular-pathogenic, but not to nonpathogenicflagellin. Biochem Biophys Res Commun. 2006;347:238-247.

16. Maltseva I, Fleiszig SJM, Evans DJ, et al. Exposure of human corneal epithelial cells to contact lenses in vitro suppresses the upregulation of human beta-defensin- 2 in response to antigens of Pseudomonas aeruginosa. Experiment Eye Res. 2007;85:142-153.

17. Robertson DM, Li L, Fisher S, et al. Characterization of growth and differentiation in a telomerase-immortalized human corneal epithelial cell line. Investigat Ophthalmol Vis Sci. 2005; 46:470-478.

18. Talarico EF. Plasma membrane calcium-ATPase isoform four distribution changes during corneal epithelial wound healing. Molec Vision. 2010;16:2259-2272.

19. Shevchenko A, Tomas H, Havlis J, Olsen JV, Mann M. In-gel digestion for mass spectrometric characterization of proteins and proteomes. Nature Protocols. 2007;1:2856-2860.

20. O'Reilly N, Bergin D, Reeves EP, McElvaney NG, Kavanagh K. Demodex-associated bacterial proteins induce neutrophil activation. Brit J Dermatol. 2012;166(4):753-760.

21. Li DQ, Lokeshwar BL, Solomon A, Monroy D, Ji Z, Pflugfelder SC. Regulation of MMP-9 production by human corneal epithelial cells. Exper Eye Res. 2001;73:449-459.

22. Jang YH, Sim JH, Kang HY, Kim YC, Lee E. Immunohistochemical expression of matrix metalloproteinases in the granulomatous rosacea compared with the non-granulomatous rosacea. J Eur Acad Dermatol Venereol. 2010;25:544-548.

23. Lu Y, Wahl LM. Oxidative stress augments the production of matrix metalloproteinase-1, cyclooxygenase-2, and prostaglandin E2 through enhancement of NF-kB activity in lipopolysaccharide-activated human primary monocytes. $J$ Immunol. 2005; 175:5423-5430. 
24. Manicone AM, McGuire JK. Matrix metalloproteinases as modulators of inflammation. Stem Cell Development Biol. 2008;19:34-41.

25. Määttä M, Kari O, Tervahartiala T, et al. Tear fluid levels of MMP-8 are elevated in ocular rosacea-treatment effect of oral doxycycline. Graefe's Arch Clinic Experiment Ophthalmol. 2006;957-962.

26. Gaudreault M, Vigneault F, Gingras M-E, et al. Transcriptional regulation of the human alpha6 integrin gene by the transcription factor NFI during corneal wound healing. Invest Ophthalmol Vis Sci. 2008;49:3758-3767.

27. Wu XY, Svoboda KK, Trinkaus-Randall V. Distribution of Factin, vinculin and integrin subunits (alpha 6 and beta 4) in response to corneal substrata. Exper Eye Res. 1995;60:445458.

28. Stepp MA. Corneal integrins and their functions. Exper Eye Res. 2006;83:3-15.

29. Suzuki K, Saito J, Yanai R, et al. Cell-matrix and cell-cell interactions during corneal epithelial wound healing. Prog Retinal Eye Res. 2003;22:113-133.

30. Zieske JD, Bukusoglu G, Gipson IK. Enhancement of vinculin synthesis by migrating stratified squamous epithelium. J Cell Biol. 1989;109:571-576.

31. Dahl M, Detmar M, Drake L, Feinstein A, Odom R, Powell F. Standard classification of rosacea: report of the National Rosacea Society Expert Committee on the Classification and Staging of Rosacea. J Am Acad Dermatol. 2002;46:584-587.

32. Baylis O, Figueiredo F, Henein C, Lako M, Ahmad S. 13 years of cultured limbal epithelial cell therapy: a review of the outcomes. J Cell Biochem. 2011;112:993-1002.

33. Gao Y-Y, Pascuale M a Di, Li W, et al. High prevalence of Demodex in eyelashes with cylindrical dandruff. Invest Ophthalmol Vis Sci. 2005;46:3089-3094.
34. Stepp M, Spurr-Michaud S, Gipson IK. Integrins in the wounded and unwounded stratified squamous epithelium of the cornea. Invest Ophthalmol Vis Sci. 1993;34:1829-1844.

35. Grose R, Hutter C, Bloch W, et al. A crucial role of beta 1 integrins for keratinocyte migration in vitro and during cutaneous wound repair. Development. 2002;129:2303-2315.

36. Lechler T, Fuchs E. Asymmetric cell divisions promote stratification and differentiation of mammalian skin. Nature. 2005;437:275-280.

37. Sapadin AN, Fleischmajer R. Tetracyclines: nonantibiotic properties and their clinical implications. $J$ Am Acad Dermatol. 2006;54:258-265.

38. Akpek EK, Merchant A, Pinar V, Foster CS. Ocular rosacea: patient characteristics and follow-up. Opbthalmol. 1997;104: 1863-1867.

39. Dursun D, Kim MC, Solomon A, Pflugfelder SC. Treatment of recalcitrant recurrent corneal erosions with inhibitors of matrix metalloproteinase-9, doxycycline and corticosteroids. Amer J Opbthalmol. 2001;132:8-13.

40. Fini ME, Parks WC, Rinehart WB. Role of matrix metalloproteinases in failure to re-epithelialize after corneal injury. Amer J Pathol. 1996;149:1287-1301.

41. Kolli S, Ahmad S, Lako M, Figueiredo F. Successful clinical implementation of corneal epithelial stem cell therapy for treatment of unilateral limbal stem cell deficiency. Stem Cells. 2010;28:597-610.

42. De Donatis A, Comito G, Buricchi F, et al. Proliferation versus migration in platelet-derived growth factor signaling: the key role of endocytosis. J Biol Chem. 2008;18;283(29):1994819956.

43. Sharma GD, He J, Bazan HE. p38 and ERK1/2 coordinate cellular migration and proliferation in epithelial wound healing: evidence of cross-talk activation between MAP kinase cascades. J Biol Chem. 2003;13;278(24):21989-21997. 